\title{
Addressing the Global Burden of Surgical Disease: Proceedings from the 2nd Annual Symposium at the American College of Surgeons
}

\author{
R. Serene Perkins $\cdot$ Kathleen M. Casey $\cdot$ \\ K. A. Kelly McQueen
}

Published online: 30 December 2009

(C) Société Internationale de Chirurgie 2009

\begin{abstract}
In the past decade, interest in surgery as a means to improve public health and engage in international service has increased significantly. International organizations, academic institutions, professional associations, and humanitarian aid organizations recognize that disparate access to surgical care affects global health and they have recently joined forces to address access to surgical care. Current initiatives focus on quantitatively defining surgical disparity, prioritizing a surgical agenda, and developing economically sustainable models for health care assistance, training, and delivery. The Global Burden of Surgical Disease Working Group (GBoSD WG) strives to (1) quantitatively define global disparity in surgical care; (2) assess unmet surgical need; (3) identify priorities; (4) develop sustainable models for improved health care delivery; and (5) advocate for a surgical presence within the global public health agenda. This article formally
\end{abstract}

\section{R. S. Perkins $(\bowtie)$}

Department of Surgery, International Surgery Program, Oregon Health and Science University (OHSU), 3181 SW Sam Jackson Park Road, L223, Portland, OR 97239-3098, USA

e-mail: sperkins429@gmail.com

\section{K. M. Casey}

Operation Giving Back, American College of Surgeons, 633 N, Saint Clair Street, Chicago, IL 60611-3211, USA

\section{K. A. K. McQueen}

Valley Anesthesiology Consultants, Ltd, Phoenix, AZ 85018, USA

\section{K. A. K. McQueen}

Harvard Humanitarian Initiative, Phoenix, AZ 85018, USA

K. A. K. McQueen

Department of Anesthesiology, Mayo Clinic, 4134 N 49th Place, Phoenix, AZ 85018, USA introduces the GBoSD Working Group and papers presented during the 2009 Symposium at the American College of Surgeons in Chicago.

\section{Introduction: existing paradigms in global surgery}

Public health initiatives have traditionally focused on disease prevention, directing most resources toward infectious disease treatment and research, rather than prioritizing the surgical specialties [1]. Recent work has revealed that appropriate surgical intervention can be provided in lowand middle-income countries (LMICs) in a cost-effective, sustainable manner that supports building healthcare infrastructure [2, 3]. Obstructed labor, postpartum hemorrhage, and trauma are leading causes of death in LMICs, and they are also leading causes of chronic disability [4]. Recent research on outcomes of surgical interventions in LMICs has opened the channels of discussion between the surgical and global public heath communities. Collaboration among international organizations, nongovernmental organizations (NGOs), academic institutions, and professional societies has begun to advance this dialogue.

Gaps in surgical care in LMICs have been addressed by NGOs for decades. Nonprofit organizations have deployed individuals and teams of volunteers to provide surgical care in communities where little or no healthcare infrastructure exists [5, 6]. International organizations have supported surgical provision in LMICs, conflict zones, and in the aftermath of disasters. Combined, the International Committee for the Red Cross (ICRC) and Médicins Sans Frontières (MSF) perform more than 150,000 surgeries annually, the majority of which are for non-war-related surgical emergencies [7, 8]. These organizations also educate local healthcare providers to ensure continuity of 
service in their absence. Much of this work has become the focus of the Global Burden of Surgical Disease Working Group.

\section{Development of the Global Burden of Surgical Disease Working Group}

A transformation in global awareness within the surgical community is driving the development of coordinated and goal-directed means to participate in and contribute to surgical public health. The Global Burden of Disease Project did not historically include surgical conditions within its scope of reporting, and there are few reliable statistics that define the "global burden of surgical disease" [9]. Only recently have individuals, academic organizations, NGOs, and international organizations begun to assess unmet surgical need and advocate for additional surgical services, education, training, and research in LIMCs. This interest has been galvanized by the World Bank's recognition of the role of surgery within global public health priorities in the Disease Control Priorities Project (DCPP), as well as dedicated resources and focused programs from the World Health Organization (WHO), the World Federation of Societies of Anaesthesia, the American College of Surgeons, and the International Society of Surgery through the World Journal of Surgery. In 2007, a small group of individuals compiled a database of surgeons, anesthesiologists, public health experts, economists, and other professionals actively engaged in promoting surgery within global public health. This record evolved into the Burden of Surgical Disease Working Group (BoSD WG). The group first met formally in April 2008 at the University of Washington and committed to contribute research and publications to support and promote awareness of this important component of global public health [9-11].

The BoSD WG continues to collaborate with the University of California San Francisco (UCSF) Bellagio Essential Surgery Group (BESG) [12, 13] and builds upon the WHO Global Initiative for Emergency and Essential Surgical Care [14] (GIEESC). The BoSD also intersects with the Harvard Humanitarian Initiative's 2009 Humanitarian Action Summit [15], which examined the role of surgery in the delivery of humanitarian aid in post-conflict settings and disaster relief [16]. The composition of the BoSD WG includes representation by individuals from four broad categories: (1) nonprofit and humanitarian organizations, (2) international organizations, (3) academic institutions, and (4) surgical and anesthesia professional societies. In the group's 2nd Annual Symposium, the topics can be classified into four focus areas that comprehensively represent the current key issues determined by the working group:
1. Anesthesia

2. Assessment, prioritization, and resource allocation

3. Collaborative partnerships for education and training

4. Subspecialty care

\section{Anesthesia}

The GBoSD WG examined global disparities in anesthesia during the 2009 meeting. Specifically, solutions for the anesthesia workforce shortage in LICs were explored by three authors. At Kijabe Hospital in Kenya, a decade's experience with "parallel training" of anesthesia providers and surgeons has resulted in the development of a Kenya Registered Nurse Anaesthesia Program and a Surgical Training Development Scheme. The MSF-Belgium group proposes a model that has shown success in training nonphysician anesthesia providers at the Hôpital Saint Nicolas in Haiti, employing "task shifting" to compensate for the severe shortage of healthcare workers in an effort to prevent avoidable deaths. Collaboration between UCSF and the Harvard Humanitarian Initiative revealed the lack of information on anesthesia provision in LMICs and led to proposed solutions to counteract poor surgical outcomes that result from the paucity of anesthesia expertise.

Assessment, prioritization, and resource allocation

In the areas of assessment, prioritization, and resource allocation, research and programmatic assessments from WHO/GIEESC, BESG, DCPP, MSF, and various academic surgical departments are presented. These organizations have begun to define a process of prioritization of those surgical conditions that constitute a significant public health burden and that can be cost-effectively and realistically addressed in a resource-constrained setting. Characterizing surgical capacity in war zones in Sri Lanka and the Democratic Republic of Congo provides unique insight into circumstances where such a prioritization model is crucial, such as systematic data collection the importance of systematic data collection detailing human and other resources, particularly in the highly dynamic setting of internal conflict in Sri Lanka. In the Congo, a conceptual framework has been proposed for estimating the burden of both emergency and elective surgical conditions, along with a method for calculating the unmet need for surgical care.

Collaborative partnerships for education and training

Academic partnerships in surgery present a different paradigm for provision of humanitarian aid. While exploring academic collaborative partnerships, the models of several existing collaborations were presented. The Brigham and 
Women's Hospital (Boston) has teamed with Partners in Health in Haiti through Zamni Lasante and in Rwanda through Ishuti Mu Buzima; The Hospital for Sick Children (Toronto) has partnered with Princess Marina Hospital in Botswana; UCSF (San Francisco) has established programs with Makarere University in Uganda; and the Vanderbilt University Medical Center (Nashville, TN) conducts educational exchange with the Baptist Medical Center Ogmboso in Nigeria and Kijabe Hospital in Kenya. These collaborations all emphasize investment in local capacity and leadership development through relationships built upon mutual respect, locally expressed needs, and research coalitions.

\section{Subspecialty care}

The role of international organizations in surgical delivery in low- and middle-income countries is described based on a survey jointly conducted by the American College of Surgeons, Operation Giving Back, and the Harvard Humanitarian Initiative. A substantial volume of surgical care is delivered by these organizations, with some providing more than 50,000 procedures annually. The study also ascertained commitment to assessing short- and longterm outcomes and to providing education and training. The challenge of evaluating surgical outcomes is significant and is discussed by authors from Operation Smile, who advocate for systematic auditing.

Specific examples from the surgical subspecialties provide additional insights into the challenges of data collection and outcomes measurement in LMICs. Representatives from orthopedics, pediatric surgery, and plastic craniofacial surgery presented data collected over several years in multiple countries on the cost-effectiveness of femur rods and widespread programs in cleft lip and palate repair. Interplast and Operation Smile presented cost-effectiveness models for facial surgery. Operation Smile shared an approach to tracking their impact and effectiveness by means of an International Cleft Outcomes Database, which encompasses 4,100 patients from 40 missions in 25 countries to date. Such databases not only begin to estimate a specific disease burden but also provide critical insights needed to develop optimal surgical treatment strategies for these conditions.

\section{Global surgery: future directions}

Ongoing collaboration among humanitarian agencies, international organizations, and university-based programs via the Global Burden of Surgical Disease Working Group will capitalize on unique and diverse experience and expertise to advance surgical care of patients worldwide. Substantial progress has been made since the group's inception in 2007 in defining the global burden of surgical disease, prioritizing surgical conditions for appropriate resource allocation, and developing sustainable models for education, training, and outcomes research.

\section{References}

1. Farmer PE, Kim JY (2008) Surgery and global health: a view from beyond the OR. World J Surg 32:533-536

2. Debas HT, Gosselin R, McCord C et al (2006) Surgery. In: Jamison D (ed) Disease control priorities in developing countries. World Bank, Washington, DC, pp 1245-1260

3. Gosselin RA, Heitto M (2008) Cost-effectiveness of a district trauma hospital in Battambang, Cambodia. World J Surg 32:2450-2453

4. World Health Organization. World Health Report 2009. Accessed online September 29, 2009 at www.who.int

5. Rinsky L (2002) Personal experiences with overseas volunteerism. Clin Orthop Relat Res 392:89-97

6. Wurlitzer F (1991) Volunteering in Western Africa. West J Med 154:730-732

7. International Committee for the Red Cross. Annual Report 2007. Accessed online March 10, 2009 at www.icrciorg

8. Médicins Sans Frontières. Annual Report 2007. Accessed on line March 10, 2009 at www.msf.org

9. Ozgediz D, Jamison D, Cherian M et al (2008) The burden of surgical conditions and access to surgical care in low- and middle-income countries. Bull WHO 86:646-647

10. Ozgediz D, Dunbar P, Mock C et al (2009) Bridging the gap between public health and surgery: access to surgical care in lowand middle-income countries. Bull Am Coll Surg 94:14-20

11. Ozgediz D, Hsia R, Weiser T et al (2008) Population health metrics for surgery: effective coverage of surgical services in low-income and middle-income countries. World J Surg 33:1-5

12. Bellagio Final Report (2007) Conference on increasing access to surgical services in resource-constrained settings in sub-Saharan Africa, Bellagio, Italy, June 4-8, 2007

13. Kampala Final Report (Bellagio Group) (2008) Increasing access to surgical services in resource-constrained settings in sub-Saharan Africa, Kampala, Uganda, July 22-24, 2008

14. World Health Organization. Global Initiative for Emergency and Essential Surgery. Accessed online on November 9, 2009 at http://www.who.int/surgery/en/

15. Harvard Humanitarian Initiative. Accessed online on November 9, 2009 at http://www.hhi.harvard.edu

16. McQueen KAK, Parmar P, Kene M et al (2009) Burden of surgical disease: strategies to manage an existing public health emergency. Pre-Hosp Disaster Med 24(Suppl 2):228-231 